\title{
Genetic characterization of pilin glycosylation in Neisseria meningitidis
}

Department of Microbiology and Parasitology, The University of Queensland, Brisbane, Queensland 4072, Australia

\author{
Peter M. Power, Louise F. Roddam, Manuela Dieckelmann, $\dagger$ \\ Yogitha N. Srikhanta, Yoke Cheng Tan, Andrew W. Berrington \\ and Michael P. Jennings
}

Author for correspondence: Michael P. Jennings. Tel: +6173365 4879. Fax: +61 733654620. e-mail: jennings@ biosci.uq.edu.au

Pili of Neisseria meningitidis are a key virulence factor, being the major adhesin of this capsulate organism and contributing to specificity for the human host. Pili are post-translationally modified by addition of an 0-linked trisaccharide, Gal $(\beta 1-4) G a I(\alpha 1-3) 2,4-d i a c e t i m i d o-2,4,6$-trideoxyhexose. In a previous study the authors identified and characterized a gene, pglA, encoding a galactosyltransferase involved in pilin glycosylation. In this study a set of random genomic sequences from $\boldsymbol{N}$. meningitidis strain MC58 was used to search for further genes involved in pilin glycosylation. Initially, an open reading frame was identified, and designated pgID (pilin glycosylation gene D), which was homologous to genes involved in polysaccharide biosynthesis. The region adjacent to this gene was cloned and nucleotide sequence analysis revealed two further genes, pgIB and pgIC, which were also homologous with genes involved in polysaccharide biosynthesis. Insertional mutations were constructed in pglB, pglC and pgID in $N$. meningitidis C311\#3, a strain with well-defined LPS and pilin-linked glycan structures, to determine whether these genes had a role in the biosynthesis of either of these molecules. Analysis of these mutants revealed that there was no alteration in the phenotype of LPS in any of the mutant strains as judged by SDS-PAGE gel migration. In contrast, increased gel migration of the pilin subunit molecules of pglB, pglC and pgID mutants by Western analysis was observed. Pilin from each of the pglB, pglC and pgID mutants did not react with a terminalgalactose-specific stain, confirming that the gel migration differences were due to the alteration or absence of the pilin-linked trisaccharide structure in these mutants. In addition, antisera specific for the $\mathrm{C} 311$ \#3 trisaccharide failed to react with pilin from the pgIB, pgIC, pgID and galE mutants. Analysis of nucleotide sequence homologies has suggested specific roles for pglB, pglC and pgID in the biosynthesis of the 2,4-diacetimido-2,4,6-trideoxyhexose structure.

Keywords: pilin, glycosylation, glycosyltransferase, lipopolysaccharide, Neisseria meningitidis

\section{INTRODUCTION}

Pili of pathogenic Neisseria spp. are typical of a family

†Present address: Institute for Biological Sciences, National Research Council of Canada, Ottawa, Ontario, Canada K1A OR6.

Abbreviations: DATDH, 2,4-diacetimido-2,4,6-trideoxyhexose; DIG, digoxigenin.

The GenBank accession number for the sequence determined in this work is AF014804. of adhesins, type IV fimbriae, found in a wide range of Gram-negative pathogens. These long polymeric proteins protrude from the bacterial surface and have a crucial role in both colonization of the host and adhesion to host cells (Virji et al., 1991; McGee \& Stephens, 1984). Although there are other accessory proteins, pili are composed primarily of thousands of subunits, called pilin. Typical of many surface proteins of pathogenic neisseriae, pili display both phase and antigenic variation (reviewed by Seifert, 1996). The gene encoding the 
pilin subunit, pilE, displays a very high degree of sequence variation, particularly towards the carboxyterminal end of the protein. This sequence variation is mediated by unidirectional recombination with DNA from several silent, non-expressed copies of the gene pils, and results in variation in adhesin function (Nassif et al., 1993; Virji et al., 1992, 1993). Pili of the pathogenic neisseriae are post-translationally modified (reviewed by Virji, 1997). Four different types of post-translational modifications have been described in detail. A phosphodiester-linked glycerol substituent has been reported at serine 93 of the pilin molecule (Stimson et al., 1996); covalently linked phosphorylcholine has been reported in N. meningitidis and N. gonorrhoeae (Wieser et al., 1998); a phosphate group has been reported at serine 68 in N. gonorrhoeae (Forest et al., 1999); and finally, pili of both $N$. meningitidis and N. gonorrhoeae are glycosylated. In N. meningitidis strain C311\#3 a detailed structural study revealed that pilin is glycosylated at serine 63 with an unusual trisaccharide molecule, $\operatorname{Gal}(\beta 1-4) \mathrm{Gal}(\alpha 1-3) 2,4$-diacetimido-2,4,6-trideoxyhexose [Gal $(\beta 1-4) \mathrm{Gal}(\alpha 1-3) \mathrm{DATDH}]$ (Stimson et al., 1995; see Fig. 8). Pili of the related pathogen N. gonorrhoeae are also glycosylated in the same region of the pilin molecule. However, the modification in $N$. gonorrhoeae is proposed to be an O-linked disaccharide Gal $(\alpha 1,3)$ GlcNAc (Parge et al., 1995), rather than the trisaccharide reported in N. meningitidis (Stimson et al., 1995). Marceau et al. (1998) have reported that a disaccharide, also proposed to be $\mathrm{Gal}(\alpha 1,3)$ GlcNAc, may be present in certain strains of $N$. meningitidis.

The precise function of glycosylation of pili has not been resolved. Since the glycosylated region of pilin is proposed to be surface exposed and has a relatively conserved amino acid sequence, it has been suggested that glycosylation may constitute 'bacterial cloaking devices against the host immune responses' (Parge et al., 1995). Indeed, the work of Hamadeh et al. (1995) suggests that the binding of naturally occurring anti-Gal antibodies to the terminal galactose may interfere in complement-mediated lysis. Recent work by Marceau \& Nassif (1999) has shown that the presence of the glycosylation at serine 63 can influence the amount of Spilin (soluble pilin) produced. Defining the precise role of pilin glycosylation in host interactions awaits the elucidation of the genes involved in the biosynthesis of these carbohydrate structures. In a previous study we reported a gene, $p g l A$, encoding a galactosyltransferase involved in the biosynthesis of the $\mathrm{Gal}(\beta 1-4) \mathrm{Gal}(\alpha 1$ 3)DATDH of N. meningitidis strain C311\#3 (Jennings et al., 1998). In this work we present the identification and characterization of another biosynthetic locus involved in the biosynthesis of this structure.

\section{METHODS}

Strains, plasmids, media and growth conditions. Meningococcal strains used in this study were MC58 (Virji et al., 1991), C311\#3 and derivatives (Virji et al., 1993), or other strains as described by Scholten et al. (1994). Meningococcal strains were grown at $37^{\circ} \mathrm{C}$ in $5 \% \mathrm{CO}_{2}$ on Brain Heart Infusion agar
Table 1. Primers used for $P C R$ of $p g / B, p g / C, p g / D$ and avtA genes

\begin{tabular}{|c|c|c|}
\hline Primer & Sequence & $\begin{array}{l}\text { Nucleotide } \\
\text { position } \\
\text { in AF14804 }\end{array}$ \\
\hline PP1 & 5'-GCGTAAGAACTTTCGTCCTC-3' & $4351-4367$ \\
\hline PP2 & 5'-GAAGAGCTCGTGCCACGGCA-3' & $4891-4909$ \\
\hline PP5 & 5'-GGATAATCTGGCGGCAGA-3' & $4036-4053$ \\
\hline PP42 & 5'-AGTCCGACGAAATCGTCC-3' & $478-495$ \\
\hline PP4 & 5'-GAGGACGAAAGTTCTTAC-3' & $4353-4370$ \\
\hline PP35 & 5'-ACAGTTTATCGCCCGAAC-3' & $1310-1327$ \\
\hline PP12 & 5'-TCCGAAGTCTATTTGGAAAA-3' & $2923-2942$ \\
\hline PP18 & 5'-GCATGTCAAACTCCCGTGTG-3' & $5102-5122$ \\
\hline PP11 & 5'-GCTGCTGAATTTGCCCAAAC-3' & $2750-2769$ \\
\hline PP15 & 5'-AAGTGTTGACCATTCCCGGA-3' & $3847-3866$ \\
\hline PP17 & 5'-GTAAGCGGGCCGCCTTCTGC-3' & $4551-4570$ \\
\hline PP24 & 5'-GACGGACAAACCATCATG-3' & 1915-1932 \\
\hline PP27 & 5'-TCAAAGCGGGCAAAATCGG-3' & $5681-5699$ \\
\hline PP30 & 5'-CGCGCCCGTGCCTATCCA-3' & $1633-1650$ \\
\hline PP35 & 5'-ACAGTTTATCGCCCGAAC-3' & $1310-1327$ \\
\hline PP50 & 5'-GGTTTTCAAACCAGAGCC-3' & $6182-6199$ \\
\hline
\end{tabular}

(BHI; Oxoid). BHI plates were made with $1 \%$ agar and supplemented with 10\% Levinthal base (Alexander, 1965). Escherichia coli strain DH5 (Sambrook et al., 1989) harbouring various recombinant plasmids was cultured in LB broth or on LB plates containing $1.5 \%$ bacteriological agar (Difco; Sambrook et al., 1989). Ampicillin (amp) and kanamycin (kan) were used at a final concentration of $100 \mu \mathrm{g} \mathrm{ml}^{-1}$.

Recombinant DNA techniques and nucleotide sequence analysis. Most recombinant DNA techniques were used as described in Sambrook et al. (1989). Nucleotide sequence analysis was performed using the PRISM Dye Terminator Sequencing Kit with AmpliTaq DNA polymerase FS (Perkin Elmer) in conjunction with a model 373a automated sequencer (Applied Biosystems). Oligonucleotide primers were synthesized on a model ABI392 synthesizer (Applied Biosystems). PCR was essentially done as described by Saiki et al. (1988). Nucleotide sequence analysis was done using MacVector (Oxford Molecular).

Southern blotting and hybridization. Restriction endonuclease $(C l a \mathrm{I})$ digested genomic DNA was separated on $0.7 \%$ agarose gels and transferred to Hybond-N+ Nylon membrane (Amersham), essentially as described in Sambrook et al. (1989). Primers shown in Table 1 were used in the PCR reactions to amplify probes for $p g l B, p g l C$, $p g l D$, and avtA (described in the legend to Fig. 1). The products were purified from agarose using a Qiaex gel extraction kit (Qiagen). The fragments were then DIG-labelled and hybridization was done using the DIG DNA Labelling and Detection Kit (Boehringer Mannheim) as recommended by the manufacturer. All restriction endonucleases and ligases were obtained from New England Biolabs.

Construction of knockout mutants of the $p g / B, p g / C$ and $p g I D$ genes. To construct insertional mutations in each of the $p g l B$, $p g l C$, and $p g l D$ genes, a kanamycin-resistance cassette (pUC4Kan: Pharmacia) was inserted into suitable unique 


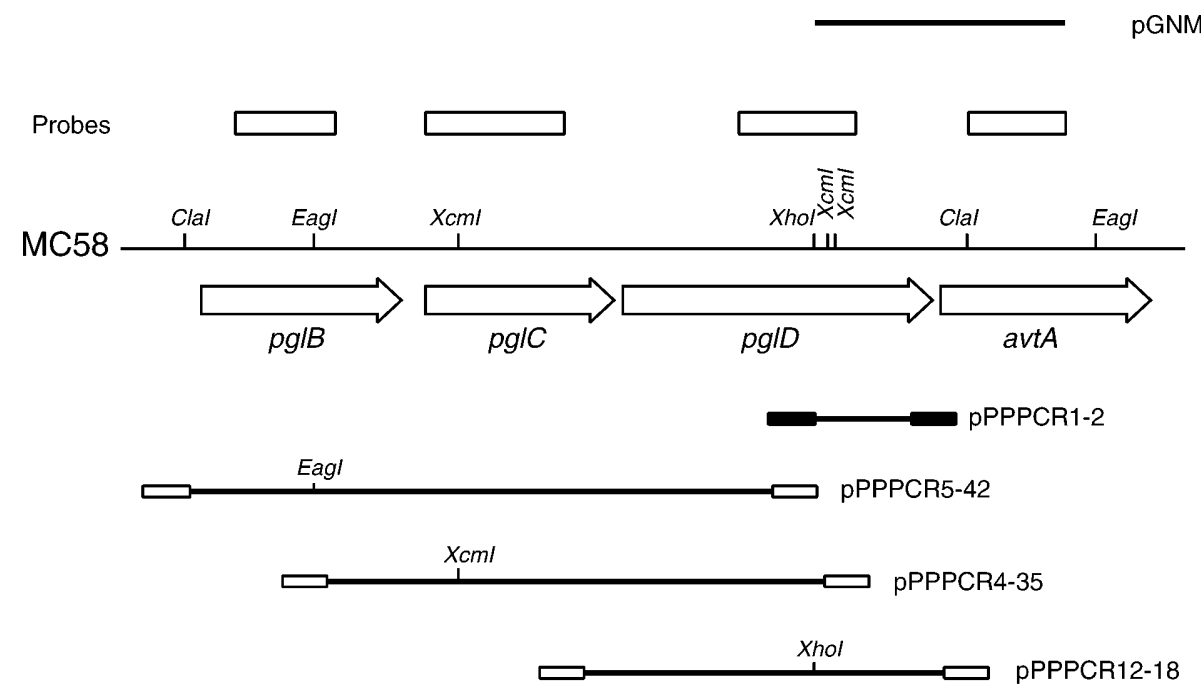

$1 \mathrm{~kb}$

\begin{abstract}
Fig. 1. Restriction, plasmid and ORF map of $p g / B, p g / C$, pglD and avtA region. The initial sequence read (pGNMBA28F) from the TIGR genome sequencing project from which this locus was identified is represented as a thick black line at the top. The line labelled MC58 represents a restriction endonuclease map of the GenBank entry AF014804. The open arrows beneath the line indicate the orientation and location of the ORFs identified in the sequence. Below the ORFs the thick black lines represent the plasmids constructed during this work. The vectors of these plasmids are represented by boxes: unfilled for pT7Blue (Novagen) and black-filled for pCRScript (Stratagene). The restriction endonuclease sites shown on these plasmids indicate where the $\operatorname{kan}^{R}$ cassettes were inserted. Rectangular boxes above the MC58 line represent the PCR products used as probes in Fig. 7. The $p g / B, p g / C, p g I D$ and avtA probes were constructed from PCR products utilizing primers PP35 and PP30, PP24 and PP11, PP15 and PP17, and PP27 and PP50, respectively.
\end{abstract}

restriction sites in the coding region of each gene (see Fig. 1). Previous work has demonstrated that this cassette has no promoter or terminator and will neither affect transcription nor have a polar effect (van der Ley et al., 1997; Jennings et al., 1995). The $p g l B$ and $p g l C$ knockouts were constructed by the digestion of pPPPCR5-42 (generated using the PCR primers PP5 and PP42 on C311\#3; Table 1) and pPPPCR4-35 (generated using the PCR primers PP4 and PP35) with the restriction enzymes EagI, and $X c m I$ respectively. The restriction enzymes were then heat-inactivated for $20 \mathrm{~min}$ at $65^{\circ} \mathrm{C}$ and the $5^{\prime}$ ends of the linearized plasmids were Klenowfilled. The plasmid containing the kanamycin-resistance cassette, pUC4Kan, was digested with HincII and the fragment containing the kanamycin-resistance gene was isolated and ligated to the linearized plasmids. The orientation of the insert was identified and plasmids containing the kanamycinresistance ORF in the same orientation as the genes were selected and linearized with either EcoRI (in the case of the $p g l B$ construct) or $B a m H I$ (for the $p g l C$ construct). These plasmids were designated pPPPCR5-42kan and pPPPCR5$35 \mathrm{kan}$ for the $p g l B$ and $p g l C$ mutants respectively. The $p g l D$ insertional mutation was created by digesting pPPPCR12-18 (generated using the PCR primers PP12 and PP18) with $X h o I$ and ligating the linearized fragment to the isolated SalI kanamycin-cassette-containing fragment derived from pUC4kan, resulting in the plasmid designated pPPPCR12$18 \mathrm{kan}$. This plasmid was then linearized with BamHI. Transformation of N. meningitidis strain C311\#3 with each of the $p g l B, p g l C$ and $p g l D$ knockouts was carried out and recombinant strains were selected by growth on BHI containing kanamycin $\left(100 \mu \mathrm{g} \mathrm{ml}^{-1}\right)$.
Pilin isolation from the pglB, pg/C and pglD knockout mutants. Pilin from each of the $p g l B, p g l C$ and $p g l D$ knockout mutants was isolated based on the method described by Wolfgang et al. (1998). Briefly, cells were collected from five heavily streaked plates, resuspended in $800 \mu \mathrm{l} 0 \cdot 15 \mathrm{M}$ ethanolamine $\mathrm{pH} 10 \cdot 5$, vortexed vigorously for $60 \mathrm{~s}$ and centrifuged at $14000 \mathrm{~g}$ for $15 \mathrm{~min}$. The supernatants were then collected, heat-killed at $56{ }^{\circ} \mathrm{C}$ for $30 \mathrm{~min}$, and $200 \mu \mathrm{l}$ of $4 \times$ loading dye added. The pilin from each strain was then separated in SDS-PAGE and semi-purified according to molecular mass, by electroelution (Bio-Rad).

Production of antisera specific for the glycosylated pilin of C311\#3 and C311\#3pgIA. Antisera directed against the pili expressed by C311\#3 and C311\#3pglA were raised in Lop/ New Zealand White rabbits as follows. Cells collected from plate cultures of each strain were resuspended in PBS at a density of $10^{11}$ c.f.u. $\mathrm{ml}^{-1}$, vortexed for $1 \mathrm{~min}$ to shear the pili, and centrifuged at $14000 \mathrm{~g}$ for $15 \mathrm{~min}$. The resulting supernatants contained similar amounts of semi-purified native pilin as confirmed by SDS-PAGE and Western analysis using the pilin-specific monoclonal antibody SM1. Each preparation of pili was combined with an equal volume of adjuvant (MPL + TDM + CWS; Sigma M6661) to a final concentration of approximately $2.5 \mathrm{mg} \mathrm{ml}^{-1}$ for inoculation into rabbits. Each rabbit received five $0.4 \mathrm{ml}$ inoculations at intervals of 2 weeks, and blood was harvested by cardiac puncture 6 weeks after the final inoculation.

Using a modification of the method of Gruber \& Zingales (1995), these sera were absorbed against meningococcal cells to enhance their specificity for glycosylated pili. Briefly, 
C311\#3 and C311\#3 pglA cells were harvested from five plates into $10 \mathrm{ml} \mathrm{PBS}$ and heat-killed at $56^{\circ} \mathrm{C}$ for $1 \mathrm{~h}$ before being washed twice in PBS and resuspended in $1.5 \mathrm{ml}$ PBS. The rabbit sera were diluted 1:50 with 1\% BSA in PBS, after which anti-C311\#3 serum was absorbed against C311\#3pglA cells and anti-C311\#3pglA serum was absorbed against C311\#3 cells. In each case $20 \mathrm{ml}$ of the diluted serum preparation was inoculated with $0.3 \mathrm{ml}$ of the cell suspension, agitated at $4{ }^{\circ} \mathrm{C}$ for $4 \mathrm{~h}$, centrifuged at $3500 \mathrm{r} . \mathrm{p} . \mathrm{m}$. for $15 \mathrm{~min}$, and the pellet discarded. Each serum underwent five cycles of absorption, followed by filtration through a $22 \mu \mathrm{m}$ Millipore filter and storage at $-20{ }^{\circ} \mathrm{C}$ until used. Specificity of the absorbed antiC311\#3 serum for the pilin-linked trisaccharide ('antitrisaccharide serum') was confirmed in three independent Western blot experiments against whole-cell lysates of C311\#3, C311\#3pglA and C311\#3galE mutants. Similarly, specificity of the absorbed anti-C311\#3pglA serum to the truncated glycan modification present on the pilin of C311\#3plgA ('anti-pglA serum') was also confirmed.

SDS-PAGE, Western blotting and LPS analysis. Analysis of LPS and pilin migration using SDS-PAGE and detection of pilinspecific bands in Western blots using SM1 have been described previously (Virji et al., 1993). The anti-trisaccharide and antipglA sera were diluted twofold (to a total dilution of $1: 100$ ) in $5 \%$ skimmed milk powder in TBS before use as primary antibody in Western analysis. Western analyses using the antitrisaccharide and anti-pglA sera were carried out as for SM1 above but using the anti-rabbit IgG secondary antibody (Sigma). All Western analysis results were confirmed in three independent experiments.

Selective detection of glycoproteins containing terminal galactose moieties. Galactose oxidase was used to create specific aldehyde groups at the $\mathrm{C} 6$ position of terminal galactose residues based on the method of Haselbeck \& Hösel (1993). Briefly, Western membranes were blocked overnight at $4{ }^{\circ} \mathrm{C}$ with $1 \%$ BSA in PBS (pH 7.5) and then washed for 5 min with $50 \mathrm{ml}$ buffer $1(0 \cdot 1 \mathrm{M}$ potassium phosphate, $\mathrm{pH} 6 \cdot 0)$. The membranes were then incubated for $15 \mathrm{~h}$ at $37^{\circ} \mathrm{C}$ with $7.5 \mathrm{U}$ galactose oxidase (Worthington) and $2 \mu 15 \mathrm{mM}$ biotinamidocaproyl hydrazide (Sigma) in $10 \mathrm{ml}$ buffer 1 , followed by three $50 \mathrm{ml}$ washes with PBS. The membranes were then blocked a second time for $1 \mathrm{~h}$ in $0.5 \%$ casein in PBS followed by three $50 \mathrm{ml}$ washes with TBS (Tris-buffered saline, $\mathrm{pH} \mathrm{7 \cdot 5),} \mathrm{before}$ immersion in conjugate solution $\left(1 \mu \mathrm{g} \mathrm{ml} \mathrm{m}^{-1}\right.$ streptavidinalkaline phosphatase in TBS) for $1 \mathrm{~h}$ at room temperature. Three $10 \mathrm{ml}$ washes with TBS were then carried out prior to immersion in colour-development solution (NBT/BCIP). Development was stopped by rinsing the membranes several times with TBS and air drying. The controls used in these experiments were pilin isolated from the C311\#3galE mutant (which is unable to synthesize UDP-galactose) and duplicate blots either without galactose oxidase or without biotinamidocaproyl hydrazide. The control blots without biotinamidocaproyl hydrazide detected a non-specific protein band slightly smaller than pilin already bound to biotin (possibly the biotin carboxyl carrier protein).

Electron microscopy. Cells were grown overnight on BHI agar as described above. Two colonies per plate were resuspended in a $10 \mu \mathrm{l}$ drop of sterile PBS ( $\mathrm{pH} 7 \cdot 2$ ). Pioloform-coated copper grids were gently placed on the drop for $1 \mathrm{~min}$, then for 3 min on a $50 \mu \mathrm{l}$ drop of $3 \%$ glutaraldehyde (in PBS), followed by washing twice in $20 \mu \mathrm{l}$ PBS and three times in $50 \mu \mathrm{l}$ water. Staining was carried out for $20 \mathrm{~s}$ in a $20 \mu \mathrm{l}$ drop of ammonium molybdate ( $1 \%$ in PBS) and the grids dried by gently blotting on filter paper. Micrographs were taken on a JEOL1010 operating at $60-80 \mathrm{kV}$.

\section{RESULTS}

\section{Identification, cloning and sequencing of $p g / B, p g / C$,} pgID and adjacent regions in strain MC58

In order to identify novel genes involved in pilin glycosylation, 400 random genomic sequences derived from a random plasmid library of N. meningitidis strain MC58 (The Institute for Genomic Research) were used to search against the combined GenBank/EMBL databases using the program BLASTX (Altschul et al., 1997). The search results were examined to identify matches with genes involved in polysaccharide biosynthesis. One of these sequences, GNMBA28F (a read of $559 \mathrm{bp}$ corresponding to the region 4351-4909 in the sequence deposited under accession number AF014804), showed a high level of similarity with the product of the $\operatorname{trs} G$ gene of Yersinia enterocolitica (Skurnik et al., 1995), and other genes involved in the biosynthesis of either lipopolysaccharide or capsular polysaccharide (see Table 2).

To further investigate this gene and its adjacent regions a cosmid library derived from strain MC58 was screened using a probe (designated pPPPCR1-2, generated using the PCR primers PP1 and PP2) derived from the GNMBA28F sequence. One of the positive clones from this library, pC4, was chosen for further analysis. The cloned region was sequenced on both strands. Analysis of $6.5 \mathrm{~kb}$ of nucleotide sequence adjacent to the GNMBA28F region revealed ORFs in the same orientation and in close proximity. These ORFs were designated $p g l B, p g l C$, $p g l D$ and avt $A$ using the nomenclature of Jennings et al. (1998). The non-coding regions between these genes were small: 133 bp between $p g l B$ and $p g l C, 48$ bp between $p g l C$ and $p g l D$, and $56 \mathrm{bp}$ between $p g l D$ and avtA, suggesting that they may be transcriptionally linked. The $\mathrm{G}+\mathrm{C}$ contents of the ORFs were $57.4 \mathrm{~mol} \%$ for $p g l B, 56.4 \mathrm{~mol} \%$ for $p g l C$, $56.5 \mathrm{~mol} \%$ for $p g l D$ and $57.1 \mathrm{~mol} \%$ for avtA. These figures are within the expected range cited for biosynthesis genes in N. meningitidis (49-56\%, Morse \& Knapp, 1992; Hoke \& Vedros, 1982). Presumptive ATG start codons were observed for all ORFs. The putative stop codon for $p g l B, p g l C$ and $a v t A$ was TAA and for pglD was TGA.

The homologies found with these genes are displayed in Table 2 and described below.

pglB. The $p g l B$ ORF is $1242 \mathrm{nt}$ in length, starting at nucleotide 556 of the determined sequence (GenBank entry AF014804) and terminating at nucleotide 1797. The putative PglB protein is 414 aa in length and has a calculated molecular mass of $44.5 \mathrm{kDa}$. A BLASTX homology search (Altschul et al., 1997) revealed two regions of distinct homology within the $p g l B$ ORF.

The first region, consisting of the N-terminal 201 aa of PglB, had highest similarity with a family of presumed glycosyltransferases. The highest scores were to a group of putative transferases from Campylobacter that were first identified as necessary for LPS biosynthesis (50/63\% identity/similarity: Wood et al., 1999; Fry et 
Table 2. Identification of proteins homologous to the products of $p g / B, p g / C, p g / D$ and avt $A$

\begin{tabular}{|c|c|c|c|c|}
\hline Putative protein & $\begin{array}{l}\text { Identity/ } \\
\text { Similarity }\end{array}$ & Organism & $\begin{array}{l}\text { Accession } \\
\text { no. }\end{array}$ & Proposed function \\
\hline \multicolumn{5}{|c|}{ PglB (414 aa, $44 \cdot 5$ kDa, pI 9.41) } \\
\hline \multicolumn{5}{|l|}{ First 200 aa } \\
\hline YvfC & $55 / 68$ & Bacillus subtilis & CAA96480 & Glycosyltransferase \\
\hline PglC & $50 / 63$ & Campylobacter jejuni & AAD51385 & Glycosyltransferase \\
\hline RfbP & $50 / 63$ & Campylobacter hyoilei & CAA62556 & Glycosyltransferase \\
\hline Cap5M & $38 / 53$ & Staphylococcus aureus & AAC46096 & Glycosyltransferase \\
\hline Cap8M & $38 / 52$ & Staphylococcus aureus & AAB49442 & Glycosyltransferase \\
\hline \multicolumn{5}{|l|}{ Last 200 aa } \\
\hline LpsB & $29 / 43$ & Caulobacter crescentus & AAC38669 & UDP-N-acetylglucosamine acyltransferase \\
\hline YvfD & $35 / 55$ & Bacillus subtilis & CAA96481 & Acetyltransferase \\
\hline PglD & $33 / 56$ & Campylobacter jejuni & AAD51386 & Acetyltransferase \\
\hline NeuD & $23 / 49$ & Escherichia coli & I55145 & Unknown \\
\hline \multicolumn{5}{|c|}{ PglC (392 aa, 43.4 kDa, pI 6.34) } \\
\hline $\mathrm{RfbE}$ & $33 / 53$ & Escherichia coli & AAB50842 & Perosamine synthetase (aminotransferase) \\
\hline StrS & $32 / 49$ & Streptomyces griseus & CAA68523 & Aminotransferase \\
\hline LpsC & $35 / 50$ & Caulobacter crescentus & AAC38670 & Perosamine synthetase (aminotransferase) \\
\hline NikC & $32 / 49$ & Streptomyces tendae & CAA75797 & L-Lysine 2-aminotransferase \\
\hline $\operatorname{Deg} \mathrm{T}$ & $32 / 50$ & Bacillus stearothermophilus & P15263 & Putative regulatory factor \\
\hline \multicolumn{5}{|c|}{ PglD (637 aa, 71.0 kDa, pI 6.98) } \\
\hline TrsG & $55 / 72$ & Yersinia enterocolitica & S51266 & $N$-Acetylgalactosamine biosynthesis \\
\hline ORF $10 / 11$ & $50 / 65$ & Vibrio cholerae $\mathrm{O} 139$ & U47057 & O-antigen and capsule biosynthesis \\
\hline $\mathrm{RfbV}$ & $46 / 63$ & Vibrio cholerae $\mathrm{O} 1$ & CAA69126 & O-antigen biosynthesis \\
\hline BplL & $46 / 60$ & Bordetella pertussis & CAA62256 & FucNAcMe biosynthesis \\
\hline WbpM & $45 / 60$ & Pseudomonas aeruginosa & AAC45867 & $\begin{array}{l}\text { Epimerase/dehydrogenase in biosynthesis } \\
\text { of Fuc2NAc }\end{array}$ \\
\hline Cap5D (Cap8D) & $36 / 54$ & Staphylococcus aureus & P39853 & $\begin{array}{l}\text { Epimerase/dehydratase involved in } \\
\text { D-FucNAcp biosynthesis }\end{array}$ \\
\hline \multicolumn{5}{|c|}{ AvtA (431 aa, 47.1 kDa, pI 4.99) } \\
\hline AvtA & $46 / 65$ & Escherichia coli & P09053 & $\begin{array}{l}\text { Valine-pyruvate aminotransferase } \\
\text { (EC 2.6.1.66) }\end{array}$ \\
\hline AspAT & $23 / 44$ & Sulfolobus solfataricus & CAA34514 & $\begin{array}{l}\text { Aspartate aminotransferase } \\
\text { (EC 2.6.1.1) }\end{array}$ \\
\hline AspAT & $21 / 39$ & Thermus aquaticus & JC4537 & Aspartate aminotransferase (EC 2.6.1.1) \\
\hline
\end{tabular}

al., 1998). These genes have recently (Szymanski et al., 1999) been shown to be involved in flagellin glycosylation (see Discussion and Table 3). There is also similarity to genes involved in O-antigen synthesis in Anabaena sp. (Korolik et al., 1997) and capsule biosynthesis in Staphylococcus aureus (Sau \& Lee, 1996; Sau et al., 1997a, b). The activity of this family of genes is based upon similarity to RfbP of Salmonella typhimurium (Wang \& Reeves, 1994, 1996), which acts to transfer galactose to an undecaprenol phosphate in the first steps of $\mathrm{O}$-polysaccharide biosynthesis. The second region of homology consists of the C-terminal 166 amino acids (from amino acid 248). This region is homologous to a family of acetyltransferases. The highest similarity with this region is LpsB of Caulobacter crescentus $(41 / 60 \%)$, which is believed to be an UDP-Nacetylglucosamine acyltransferase involved in LPS biosynthesis (Awram \& Smit, 1998). In common with this family of genes, this area of similarity contains an isoleucine patch which is speculated to play an important structural role in the function of these enzymes (Dicker \& Seetharam, 1992). The two regions of the putative PglB also have distinct $\mathrm{G}+\mathrm{C}$ contents, the $\mathrm{N}$ terminal region having a $\mathrm{G}+\mathrm{C}$ content of $52 \mathrm{~mol} \%$ and the $\mathrm{C}$-terminal region a $\mathrm{G}+\mathrm{C}$ content of $62 \cdot 2 \mathrm{~mol} \%$.

pglC. The second ORF, pglC, is $1176 \mathrm{nt}$ in length, starting at nucleotide 1930 and ending at nucleotide 3105. The putative PglC protein is 392 aa in length and has a calculated molecular mass of $43.4 \mathrm{kDa}$. PglC is most similar $(38 / 53 \%)$ to a DegT homologue in Methanobacterium thermoautotrophicum (Smith et al., 1997). This family of genes, although once thought to play a regulatory role, are now proposed to be aminotransferases (Thorson et al., 1994). The putative PglC has high similarity with a number of pyridoxal-binding dehydrases and aminotransferases and contains the aminotransferase class III pyridoxal-phosphate attach- 


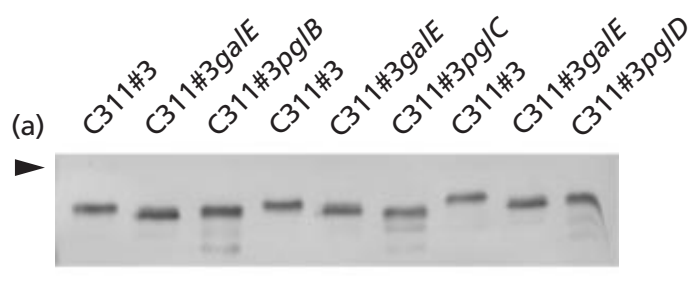

(b)

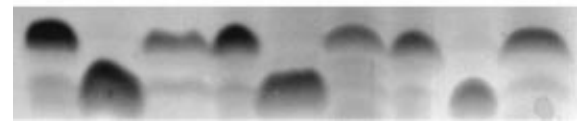

Fig. 2. Analysis of the migration of pilin and LPS of the C $311 \# 3$ derivatives. (a) Western blot analysis of the migration of pilin isolated from C311\#3, C311\#3galE and C311\#3pg/B, pg/C and pglD mutants. Pilin was identified by the use of monoclonal antibody SM1 specific for class I pili of Neisseria. (b) Silverstained gel showing the relative migrations of LPS of C311\#3 and derivatives. Sample are labelled at the top of the figure. The position of prestained low-molecular-mass marker ( $21.5 \mathrm{kDa}, \mathrm{Bio}-\mathrm{Rad})$ is indicated by the arrowhead to the left of the figure.

ment site (PROSITE PS00600; Appel et al., 1994) that is common to the various members of this group. A number of the proteins in this family are involved in the synthesis of amino sugars, such as RfbE of E. coli in perosamine synthesis (Bilge et al., 1996; Stroeher et al., 1995).

pgID. The third ORF, $p g l D$, begins at nucleotide 3153 and terminates at nucleotide 5063 . This constitutes an ORF of $1911 \mathrm{bp}$ and translation yields a peptide of 637 aa with a calculated molecular mass of $71 \cdot 0 \mathrm{kDa}$. The putative PglD protein is highly similar to a family of proteins proposed to be dehydratases involved in LPS and $\mathrm{O}$-antigen biosynthesis. It is most similar $(55 / 72 \%)$ to TrsG of Yersinia enterocolitica (Skurnik et al., 1995).

avtA. The last ORF starts at nucleotide 5119 of the determined sequence and is $1293 \mathrm{bp}$ in length, terminating at nucleotide 6411. The putative AvtA protein is 431 aa long, has a calculated molecular mass of $47 \cdot 1 \mathrm{kDa}$ and is homologous $(46 / 65 \%)$ with AvtA from E. coli (Sofia et al., 1994). AvtA is an alanine-tovaline aminotransferase and has not been implicated in any saccharide biosynthesis.

\section{Construction and analysis of pgl::kan mutant strains}

In order to determine whether $p g l B, p g l C$ or $p g l D$ played a role in either LPS biosynthesis or pilin glycosylation, mutants were constructed by the insertion of a kanamycin-resistance $\left(\mathrm{kan}^{\mathrm{R}}\right)$ cassette into restriction endonuclease sites present in each of the coding regions (see Fig. 1). These insertional mutant constructs were then used to transform strain C311\#3, a meningococcal strain with a well-characterized pilin structure, so that the inactive alleles were transferred to the chromosome by homologous recombination. The presence of the inactive allele was confirmed, both by Southern hybridization and by PCR of the mutated alleles (see Methods; results not shown).

LPS phenotype of $p g / B, p g / C$ and $p g I D:$ : kan mutant strains. Many of the genes involved in meningococcal LPS biosynthesis have been described (Jennings et al., 1999). However, there is still the potential for novel structures to be identified. To determine whether $p g l B$, $p g l C$ or pglD affected LPS biosynthesis, the LPS of the mutant derivatives was analysed by SDS-PAGE. This revealed that there were no alterations in migration of the LPS molecule isolated from any of the mutant strains when compared to the parental strain and the control strain C311\#3galE::kan (Fig. 2b). These results indicate that neither $p g l B$, $p g l C$ or $p g l D$ is involved in LPS biosynthesis.

Analysis of the migration of pilin from the $p g / B, p g / C$ and pgID:: kan mutants of strain C311\#3. Since a role for $p g l B$, $p g l C$ or $p g l D$ in LPS biosynthesis could not be detected, we sought to test the alternative hypothesis that these genes were involved in pilin glycosylation. The structure of the trisaccharide moiety was determined in the meningococcal strain C311\#3 and found to be Gal( $\beta 1$ 4)Gal( $\alpha 1-3) \mathrm{DATDH}$ (Stimson et al., 1995). Analysis of the previously described $p g l A$ and galE mutants of C311\#3 demonstrated that modifications of the trisaccharide resulted in altered pilin migration in SDSPAGE (Jennings et al., 1998). Analysis of pilin of the $p g l B, p g l C$ and $p g l D$ mutant derivatives of C311\#3 showed that in all three cases, the pilin migrated further than those from the parent strain (Fig. 2a). This observation suggested that $p g l B, p g l C$ and $p g l D$ may affect pilin glycosylation.

Sequencing of the pilE gene of the pglB, pg/C and pgID:: kan mutants of strain C311\#3. The gene encoding the pilin subunit, pilE, displays a high degree of sequence variation, particularly towards the carboxy-terminal end of the protein (Seifert, 1996). Alterations in the sequence of pilE result in alterations in pilin migration in SDS-PAGE. Therefore, the pilE genes of the $p g l B, p g l C$ and $p g l D::$ kan mutants of $C 311 \# 3$ were sequenced and the sequences compared with the pilE sequence of the parental strain C311\#3 (GenBank accession number L22639). The sequences (results not shown) confirmed that there was no difference in the pilE genes of the mutants compared to the parental gene, indicating that the differences observed in pilin migration from these mutants must be due to alterations in post-translational modifications.

Pilin of the $p g / B, p g / C$ and $p g / D$ mutants is not detected by a terminal galactose-specific method. In order to determine whether the change in pilin migration was due to an alteration in the trisaccharide modification, as opposed to one of the other known pilin modifications, we examined the $p g l B, p g l C$, and $p g l D$ mutant derivatives using a terminal-galactose-specific detection system (see Methods). Semi-purified pilin (see Methods) extracted from C311\#3, and its galE, pglA, pglB, pglC and $p g l D$ mutants, was separated by SDS-PAGE and transferred to PVDF membrane. Pilins containing terminal ga- 


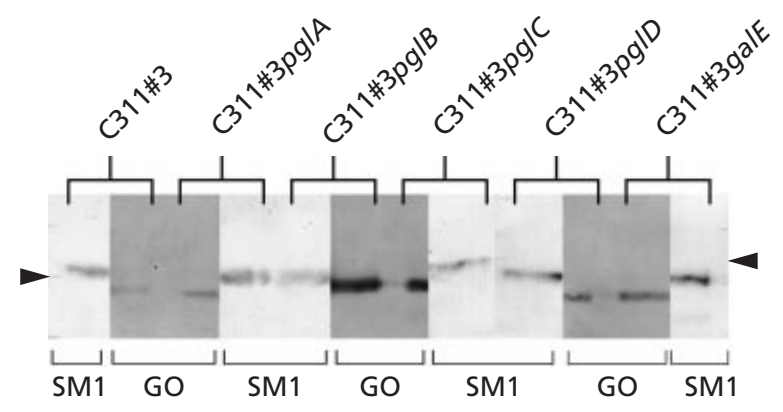

Fig. 3. Split-lane gels of pilin isolated from $\mathrm{C} 311 \# 3$ derivatives detected with SM1 and the non-specific band detected with streptavidin-alkaline phosphatase conjugate. Semi-purified pilins extracted from C311\#3, C311\#3galE and C311\#3pglB, $p g / C$ and $p g / D$ mutants (as indicated at the top of the figure) were loaded on $15 \%$ SDS-PAGE gels and transferred to PVDF. The membrane was then cut down the middle of each lane so that two detection methods could be applied to each sample. Pilin in panels labelled SM1 was identified with the monoclonal antibody SM1. Panels labelled GO were treated as for galactose-specific detection (without the galactose oxidase) to identify the non-specific band, clearly demonstrating that pilin bands do not co-migrate with the non-specific band. Arrowheads indicate the $20 \mathrm{kDa}$ molecular mass marker (BenchMark, GibcoBRL).

lactose moieties were then selectively detected by the use of biotinamidocaproyl hydrazide following galactose oxidase treatment, which creates aldehyde groups specifically on terminal galactose residues, resulting in the incorporation of biotin specifically into structures containing a terminal galactose residue (Haselbeck \& Hösel, 1993). On establishing this method it became clear that the semi-purified pilin preparations contained a non-specific protein band (possibly a biotin carboxyl carrier protein) that was detected in the absence of biotin hydrazide (results not shown). The predicted molecular mass of the biotin carboxyl carrier protein in N. meningitidis strain Z2491, based on the preliminary Sanger genome sequence data, is $15.9 \mathrm{kDa}$, which is consistent with its migration in SDS-PAGE. The presence of this non-specific band is evidently due to the coisolation of this protein in the semi-purified pilin preparations. To demonstrate that this non-specific band did not co-migrate with pilin, and therefore that pilin could be detected by the galactose-specific method, a split-band experiment was carried out (Fig. 3). In this experiment, following separation of pilin by SDS-PAGE, each lane was cut vertically. Pilin was then detected using SM1 and the non-specific band was detected with biotin/streptavidin. In all cases the non-specific band did not co-migrate with pilin. The increased concentration of the non-specific band in the $p g l B$ and $p g l C$ mutant pilin preparations resulted from a higher proportion being co-purified due to a smaller difference between the molecular mass of pilin from these mutant strains and the non-specific band.

Having established that the non-specific band was not pilin and did not co-migrate with any of the pilin samples, we then used this method to detect pilin

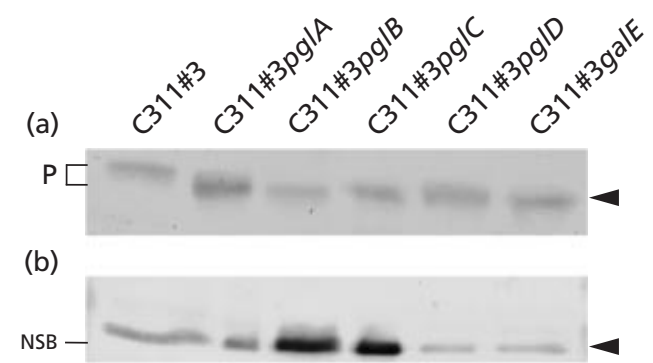

(c)

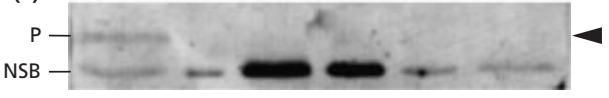

Fig. 4. Galactose-specific labelling of pilin from the $\mathrm{C} 311 \# 3$ derivatives. Semi-purified pilin extracted from C311\#3, C311\#3galE and C311\#3pg/B, pg/C and pglD mutants (as indicated at the top of the figure) was loaded on $15 \%$ SDSPAGE gels and transferred to PVDF. Pilin (P) was identified in (a) using the monoclonal antibody SM1 against class I pili of Neisseriae, and in (c) by oxidation with galactose oxidase; (b) was treated as for (c) but without galactose oxidase. Seen exclusively in (b) and (c) is the lower non-specific band (NSB, possibly a biotin-binding protein). Arrowheads indicate the $20 \mathrm{kDa}$ prestained molecular mass marker (BenchMark, GibcoBRL).

isolated from C311\#3 and its derivatives. The wild-type pilin of C311\#3 was detected using this method but not the pilin isolated from the $p g l B, p g l C, p g l D, p g l A$ or galE mutants (Fig. 4c). The specificity of the detection method was shown by the lack of reactivity of C311\#3 pilin in the absence of galactose oxidase (Fig. 4b). The detection of isolated pilin with the monoclonal antibody SM1 (Fig. 4a) and the lack of detection with the terminal galactose-specific method strongly suggests that the pilin produced by the $p g l A, p g l B, p g l C$ and $p g l D$ mutants of C311\#3 (as well as its galE mutant, which is unable to synthesize UDP-galactose) do not contain a terminal galactose residue.

Antiserum specific for the C311\#3 trisaccharide does not react with pilin isolated from the C311\#3 pglA, pglB, pg/C, pgID or galE mutants. The specificity of anti-trisaccharide serum was confirmed in Western blot experiments in which it bound pilin isolated from C311\#3 but not pilin isolated from C311\#3pglA or C311\#3galE (see Methods and Fig. 5b). Nucleotide sequencing experiments have shown previously that the amino acid sequences of the pilin expressed by C311\#3 and C311\#3pglA are identical except for the presence of the complete trisaccharide structure on C311\#3 (see Fig. 8), indicating that the antitrisaccharide serum specifically recognizes the C311\#3 trisaccharide. Similarly, anti-pglA serum was shown to bind pilin isolated from C311\#3pglA and C311\#3galE but not pilin isolated from C311\#3 (see Methods and Fig. 5c), indicating that anti-pglA is specific for the truncated glycosyl structures of C311\#3pglA and C311\#3galE (Fig. 8).

Western blots of semi-purified pilin from C311\#3, C311\#3 pglA, pglB, pglC, pglD and galE mutants were probed with SM1 (Fig. 5a), anti-trisaccharide serum and 


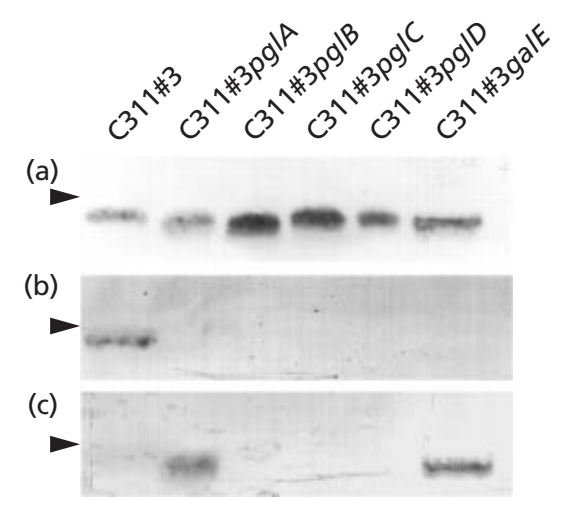

Fig. 5. Detection of pilin using the anti-trisaccharide and anti-pglA sera. Semi-purified pilins extracted from C311\#3, C311\#3galE and the C311\#3pg/B, pg/C and pglD mutants (as indicated at the top of the figure) were loaded on $12 \%$ SDSPAGE gels and transferred to nitrocellulose. Pilin was identified in (a) using the monoclonal antibody SM1 against class I pili of Neisseriae, in (b) with anti-trisaccharide serum and in (c) with anti-pglA serum (see Methods). Arrowheads indicate the $20 \mathrm{kDa}$ prestained molecular mass marker (BenchMark, GibcoBRL).

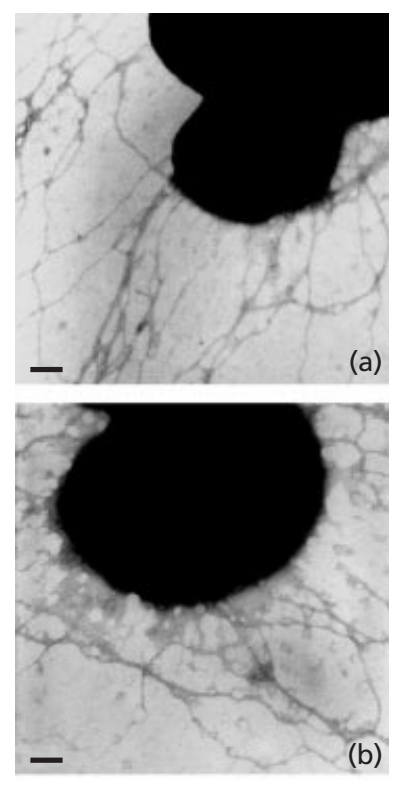

Fig. 6. Electron micrographs of pili of (a) $\mathrm{C} 311 \# 3$ and (b) C311\#3pg/B::kan derivative. Bars, $100 \mathrm{~nm}$.

anti-pglA serum. Anti-trisaccharide serum reacted with C311\#3 pilin but not with pilin isolated from the C311\#3 pglA, pglB, pglC, pglD or galE mutants (Fig. 5b), indicating that the complete pilin-linked trisaccharide structure was only present in the wild-type. Anti-pglA serum reacted with C311\#3pglA and C311\#3galE pilin but not with wild-type pilin nor pilin isolated from any of the C311\#3 pglB, pglC or $p g l \mathrm{D}$ mutants (Fig. $5 \mathrm{c}$ ). This confirmed in each case that pilin from the $p g l B, p g l C$ and $p g l D$ mutants was not modified either by the complete pilin-linked trisaccharide structure or by a truncated form such as is present in the C311\#3pglA and C311\#3galE mutants.

Electron micrographs of the pili produced by the $p g / B, p g / C$ and pgID::kan mutants show no effect on pilus morphology. To determine whether the $p g l B, p g l C$ and $p g l D$ mutant derivatives of strain C311\#3 still expressed pili located on the cell surface, and whether these pili had altered morphology, the pili of the $p g l B, p g l C$ and $p g l D::$ kan mutants were observed by electron microscopy. All mutant derivatives were found to surfaceexpress pili. A large degree of variation (within samples) in both piliation level and presence or absence of bundles was encountered. In general, there were no consistent differences in pilus morphology or piliation level of the $p g l B, p g l C$ and $p g l D::$ kan mutants in comparison to wild-type. A representative electron micrograph of the pili of the $p g l B$ mutant compared to C311\#3 is shown in Fig. 6.

\section{Distribution of the $p g / B, p g / C, p g / D$ and avt $A$ genes amongst different $\boldsymbol{N}$. meningitidis strains and other species of Neisseria}

To determine the potential of other $N$. meningitidis strains and Neisseria species to make glycosylated pilin structures, a collection of strains and species was surveyed using the probes described in the legend of Fig. 1. The resulting Southern blot (Fig. 7a) clearly demonstrates the presence of $p g l B, p g l C, p g l D$ and avtA in all of the N. meningitidis strains tested. Furthermore, Southern blots performed using single isolates of pathogenic and non-pathogenic Neisseria spp. revealed that sequences homologous to $p g l B, p g l C, p g l D$ and avt $A$ were present in $N$. subflava, N. gonorrhoeae and $N$. lactamica L19 (Fig. 7b). In addition, N. cinerea, N. pharyngis and N. lactamica L12 had homologues to either two or three of the four genes.

\section{DISCUSSION}

Glycosylation of prokaryotic proteins has been considered to be highly unusual. There are now, however, an increasing number of reports not only of prokaryotic protein glycosylation but also of the importance of glycoproteins in pathogenicity (reviewed by Tuomanen, 1996). To date, the best-characterized prokaryotic glycoprotein is the pilin of N. meningitidis. The structure of the N. meningitidis strain C311\#3 pilin-linked trisaccharide has been elucidated by carbohydrate analysis and mass spectrometry of tryptic peptides (reviewed by Virji, 1997; see Fig. 8). Marceau et al. (1998) have alternatively identified a disaccharide modification on N. meningitidis. In a recent paper Jennings et al. (1998) described the first gene involved in the glycosylation of pilin. The gene identified, $p g l A$, was found to encode a pilin-specific glycosyltransferase involved in the addition of galactose to the trisaccharide.

In this study we have characterized a genetic locus, $p g l B C D$, from $N$. meningitidis that appears to encode additional enzymes involved in pilin glycosylation. 


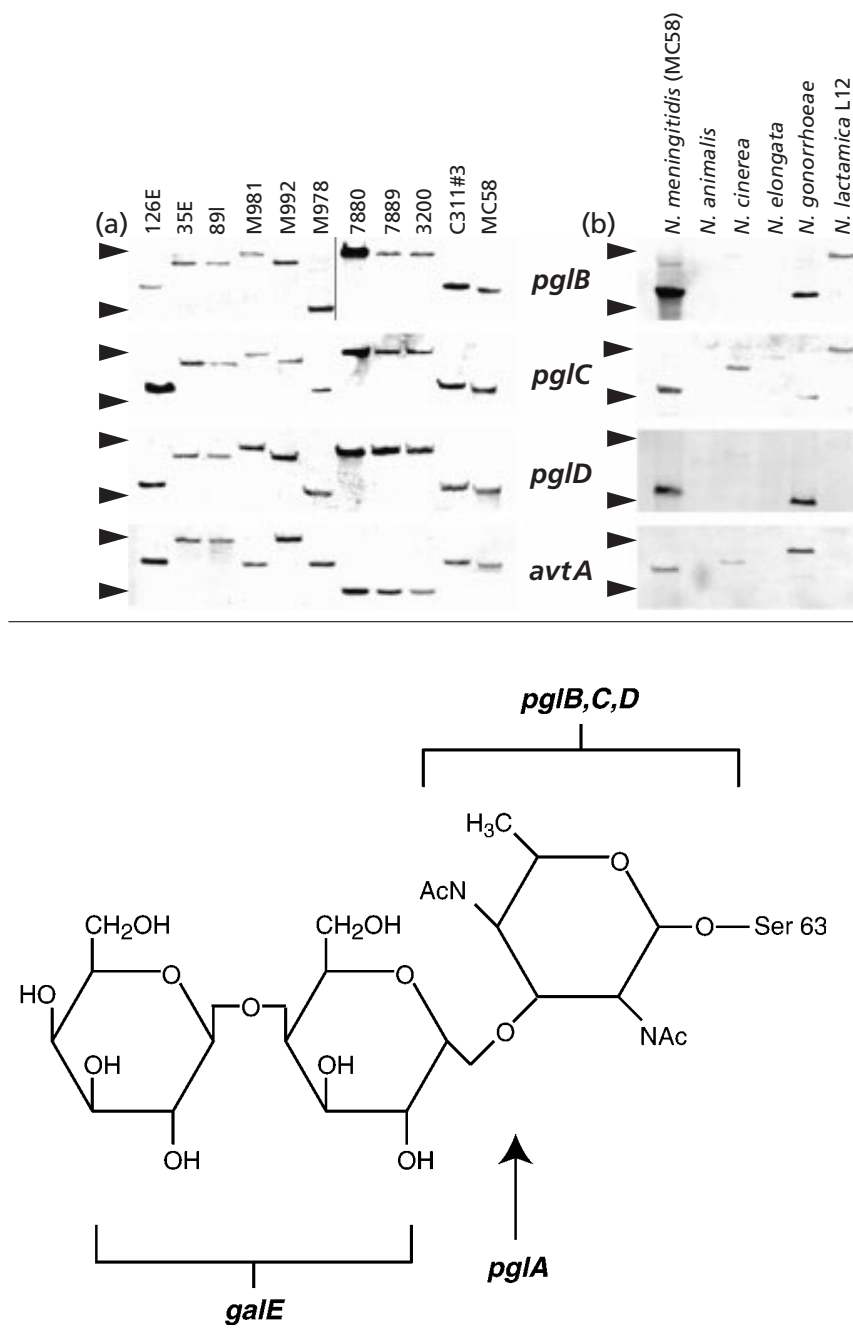

Fig. 8. Proposed structure of the pilin-linked trisaccharide of C311\#3 and its derivatives (see Stimson et al., 1995). The arrow indicates the proposed truncation of the trisaccharide structure in galE and pglA mutant strains. The bracket at the top indicates the DATDH residue; the genes proposed to be involved in biosynthesis of this residue are indicated above.

Analysis of the incomplete N. meningitidis strain Z2491 genome (Sanger Centre) revealed that the $p g l A$ and the $p g l B C D$ loci are unlinked $(600 \mathrm{~kb}$ apart). Three of the four ORFs identified in the new locus show significant homology to proteins implicated in LPS and capsule biosynthesis. Analysis of the migration of the pilin subunit of each of the $p g l B, p g l C$ and $p g l D$ mutants indicated an alteration in molecular mass. Nucleotide sequence analysis confirmed that this was not due to amino acid sequence variation of PilE, indicating posttranslational modification as the most likely cause of the altered migration This was confirmed by two independent methods. Firstly, use of a terminal galactosespecific stain confirmed that the post-translational modification that was affected was the pilin-linked trisaccharide, which was either absent or altered in all three of the mutant strains. The second method confirmed the absence of the complete pilin-linked
Fig. 7. Distribution of $p g / A, p g / B, p g / C$ and avtA in various $N$. meningitidis strains and Neisseria species. The panels show the results of Southern hybridization experiments with probes specific for the $p g / B, p g / C, p g / D$ and avtA genes (See Methods). Chromosomal DNA (0.2-1.0 $\mu \mathrm{g})$ from a range of strains was digested with Clal and separated on a $1 \%$ agarose gel. The arrowheads on the left of the figure indicate the positions of molecular mass markers (8 kbp and $5 \mathrm{kbp}$ in ascending order). Slight variations in band intensity are in direct proportion to the amount of DNA in each lane as judged by ethidium bromide staining. The $N$. meningitidis strains (a) and Neisseria species (b) used are indicated at the top of the figure. 
PglB protein is highly homologous with a family of putative glycosyltransferases. These glycosyltransferases are proposed to transfer a sugar residue (usually galactose) to the lipid precursor undecaprenol phosphate (Wood et al., 1999; Fry et al., 1998; Drummelsmith \& Whitfield, 1999). This region of PglB also contains the hydrophobic domain that is required by these proteins for interaction with the undecaprenol phosphate lipid carrier (Wood et al., 1999). The transfer of a nucleotide sugar to a lipid carrier is often the first step in oligosaccharide biosynthesis. It is therefore suggested that PglB may be required in the transfer of the first sugar residue either to an undecaprenol phosphate lipid carrier or directly to the serine 63 of pilin. This transfer may represent the initial step in the glycosylation of pilin.

The carboxy-terminal 168 aa stretch of the putative PglB protein shows strong homology with a family of acetyltransferases (e.g. UDP- $N$-acetylglucosamine and sialic acid transfer) required for LPS and capsular polysaccharide biosynthesis (Awram \& Smit, 1998; Fry et al., 1998; Annunziato et al., 1995). Typical of this family of acetyltransferases, PglB contains an isoleucine patch which is a common signature associated with acetyltransferase function (Dicker \& Seetharam, 1992). The biosynthesis of acetamido sugars such as the 2,4diacetamido sugar residue found in the pilin-linked trisaccharide requires acetylation of the amino groups. Therefore, this region of PglB is suggested to be involved in the acetylation at $\mathrm{C} 2$ or $\mathrm{C} 4$ of the diacetamido sugar constituent of the pilin-linked trisaccharide.

Thus it appears that PglB may be a bifunctional protein involved in the early steps of trisaccharide biosynthesis, namely in the biosynthesis of the first sugar residue and its transfer either to an undecaprenol phosphate lipid carrier or to serine 63 of the pilin. The pilin produced by the $p g l B::$ kan mutant would be expected to be devoid of the complete trisaccharide structure. The altered migration, the absence of a terminal galactose residue and the failure of pilin isolated from the $p g l B::$ kan mutant to react with either anti-trisaccharide or anti-pglA sera support this hypothesis.

The second ORF identified in the locus, $p g l C$, shows significant homology with a family of aminotransferases involved in the synthesis of amino sugars (Stroeher et al., 1995). The putative PglC protein is strongly similar to $\mathrm{RfbE}$ of E. coli, which is a probable perosamine synthetase. RfbE is believed to catalyse the transamination of GDP-4-keto-6-deoxymannose to GDP-4amino-4,6-dideoxymannose (perosamine; Stroeher et al., 1995). PglC is also highly similar to NikC from Streptomyces Tü901, which has been shown to encode an L-lysine 2-aminotransferase required for the biosynthesis of nikkomycin (Bruntner \& Bormann, 1998). All of these proteins belong to a novel class of pyridoxamine- or pyridoxal-phosphate-dependent dehydrases and aminotransferases, based on the presence of a pyridoxal-phosphate-binding motif (PS00600; Appel et al., 1994). This is consistent with the findings of Matsuhashi \& Strominger (1966), where a pyridoxal- phosphate-dependent transaminase is required for the biosynthesis of an acetamido sugar. This leads us to propose that in N. meningitidis PglC is required for the transamination of either $\mathrm{C} 2$ or C4. Therefore, we would expect the $p g l C::$ kan mutant to be unable to synthesize a complete DATDH residue, resulting in pilin with either a single sugar residue or no glycosylation depending on the substrate specificity of the glycosyltransferases. The possibility of complete absence of glycosylation on the serine 63 of pilin isolated from the pglC::kan mutant is supported by its increased migration, its failure to be detected by a terminal galactosespecific stain and its failure to be detected by either antitrisaccharide or anti-pglA sera.

The $p g l D$ gene product is highly similar to proteins essential for either LPS or O-antigen amino sugar biosynthesis (Skurnik et al., 1995; Comstock et al., 1996). These proteins all have maximum homology in their carboxy-termini and are divergent in their aminotermini. Fallarino et al. (1997) suggested that this was due to the amino-terminus being involved in specificity and the carboxy-terminus incorporating the functional domain of these proteins. The putative PglD protein shares these characteristics and also contains the two distinct motifs, both for binding NAD, that have been suggested to be a requirement for enzyme function (Skurnik et al., 1995). PglD demonstrated high similarity to the $\operatorname{Trs} G$ from Y. enterocolitica, which is proposed to be an epimerase or dehydratase involved in $\mathrm{N}$-acetylgalactosamine biosynthesis (Skurnik et al., 1995). The BplL protein of Bordetella pertussis is also highly similar to PglD and itself has some strong similarities to a number of dTDP-glucose 4,6-dehydrases (Bechthold et al., 1995; Linton et al., 1995). Based on this observation, Allen \& Maskell (1996) suggest that BplL is responsible for the biosynthesis of FucNAcMe (a 6-deoxy derivative of galactose). They further suggest that this group of enzymes are generally required for the synthesis of 6deoxy and dideoxy sugars.

It seems likely, therefore, that PglD is involved in synthesis of the DATDH moiety of the pilin-linked trisaccharide as a dehydratase acting on C2, C4 or C6. Therefore, we would expect a similar modification (i.e. one or no sugar residues) to be present on the $p g l D:: \mathrm{kan}$ mutant pilin, as is expected for the $p g l C:$ : kan mutant. This hypothesis is again supported both by the decreased migration of pilin isolated from the mutant compared to the wild-type, and also by the failure of this pilin to be detected by a terminal galactose-specific method, antitrisaccharide or anti-pglA sera.

The final ORF in the identified locus, AvtA, has a high degree of similarity to putative alanine-to-valine aminotransferases (e.g. AvtA of E. coli; Sofia et al., 1994). These genes are involved in amino acid biosynthesis and have not been implicated in sugar biosynthesis. Several attempts were made to knock out the avtA gene of $N$. meningitidis, but they were unsuccessful, indicating a possible essential housekeeping function for this protein. Therefore, the role (if any) of this gene in pilin glycosylation could not be determined. 
Table 3. Comparison of the neisserial pilin glycosylation genes with a flagellin glycosylation locus identified in Campylobacter jejuni

Numbers denote percentage identity/similarity between genes.

\begin{tabular}{|lllll|}
\hline \multirow{2}{*}{ C. jejuni gene } & \multicolumn{4}{c|}{ Neisserial pilin glycosylation gene: } \\
\cline { 2 - 5 } & pglA & pglB* & pglC & pglD \\
& & & & \\
pglA & $30 / 49$ & & & \\
pglC & & $51 / 64$ & & \\
pglD & & $32 / 56$ & & \\
pglE & & & $27 / 43$ & \\
pglF & & & & $33 / 49$ \\
\hline
\end{tabular}

*Homology to C. jejuni pglC and $p g l D$ is in the amino-terminal and carboxy-terminal region, respectively (see text).

The functions proposed for the $p g l B, p g l C$ and $p g l D$ genes, and their close proximity to each other, suggest that they act together in the biosynthesis of the acetamido sugar residue of the pilin-linked trisaccharide. The biosynthesis of an acetamido sugar, as described by Matsuhashi \& Strominger (1966), is initiated by dehydration (PglD dependent), followed by transamination (PglC dependent) and transacetylation (PglB dependent) of a single carbon. This acetamido sugar could then be transferred to either a lipid carrier or the serine 63 of pilin by PglB. As the DATDH sugar residue is a diacetamido sugar, we suggest that $p g l B$, $p g l C$ and $p g l D$ may act on a precursor that is either a C2 or a C4 acetamido sugar (for example glucosamine or fucosamine).

A survey to detect the presence of $p g l B, p g l C, p g l D$ and avt $A$, using Southern analysis, revealed that these genes were present in all of the N. meningitidis strains tested, in N. gonorrhoeae and also in other species of Neisseria. This was also found with the previously identified $p g l A$ gene, suggesting that pilin glycosylation may be common amongst neisserial species (Jennings et al., 1998). During the preparation of this paper, Szymanski et al. (1999) reported the identification of a Campylobacter jejuni locus involved in the biosynthesis of an undefined glycosylation on the flagella of this organism. Although the sequence identities were not amongst the highest matches found, the genes were present in the same order as the $p g l B C D$ locus described here (see Table 3). Szymanski et al. (1999) not only implicated the locus in glycosylation of flagella, but also of other proteins, confirming that their locus represents a general glycosylation pathway.

In conclusion, this study has identified three genes, $p g l B$, $p g l C$ and $p g l D$, involved in pilin glycosylation, in addition to the previously identified $p g l A$ gene (Jennings et al., 1998). To date, the precise functions that we have predicted for $p g l B, p g l C$ and $p g l D$ are based on amino acid sequence homologies with genes in the databases that are involved in the biosynthesis of similar chemical structures to the pilin-linked trisaccharide. Currently we are obtaining structural data and biochemical evidence to support the gene functions that we have proposed.

\section{ACKNOWLEDGEMENTS}

Work in M.P. J.'s laboratory is supported by a Project Grant from the NHMRC (981423). We thank Rick Webb for assistance with electron microscopy, Mumtaz Virji for mAb SM1, Craig Dickfos for assistance with production of antisera and the N. meningitidis Sequencing Group at the Sanger Centre (ftp://ftp.sanger.ac.uk/pub/pathogens/nm/).

\section{REFERENCES}

Alexander, H. E. (1965). The Haemophilus group. In Bacterial and Mycotic Infections of Man, pp. 724-741. Edited by R. J. Dabos \& J. G. Hirsch. London: Pitman Medical Publishing Co.

Allen, A. \& Maskell, D. (1996). The identification, cloning and mutagenesis of a genetic locus required for lipopolysaccharide biosynthesis in Bordetella pertussis. Mol Microbiol 19, 37-52.

Altschul, S. F., Madden T. L., Schäffer A. A., Zhang, J., Zhang, Z., Miller, W. \& Lipman, D. J. (1997). Gapped BLAST and PSI-BLAST : a new generation of protein database search programs. Nucleic Acids Res 25, 3389-3402.

Annunziato, P. W., Wright, L. F., Vann, W. F. \& Silver, R. P. (1995). Nucleotide sequence and genetic analysis of the neuD and neuB genes in region 2 of the polysialic acid gene cluster of Escherichia coli K1. J Bacteriol 177, 312-319.

Appel, R. D., Bairoch, A. \& Hochstrasser, D. F. (1994). A new generation of information retrieval tools for biologists: the example of the ExPASy WWW server. Trends Biochem Sci 19, 258-260.

Awram, P. \& Smit, J. (1998). The Caulobacter crescentus paracrystalline $S$-layer protein is secreted by an $\mathrm{ABC}$ transporter (type I) secretion apparatus. J Bacteriol 180, 3062-3069.

Bechthold, A., Sohng, J., Smith, T. M., Chu, X. \& Floss, H. G. (1995). Identification of Streptomyces violaceoruber Tü22 genes involved in the biosynthesis of granaticin. Mol Gen Genet 248, 610-620.

Bilge, S. S., Vary, J. C., Dowell, S. F. \& Tarr, P. I. (1996). Role of the Escherichia coli O157:H7 side chain in adherence and analysis of an $r f b$ locus. Infect Immun 64, 4795-4801.

Bruntner, C. \& Bormann, C. (1998). The Streptomyces tendae Tü901 L-lysine 2-aminotransferase catalyses the initial reaction in nikkomycin D biosynthesis. Eur J Biochem 254, 347-355.

Comstock, L. E., Johnson, J. A., Michalski, J. M., Morris, J. G. \& Kaper, J. B. (1996). Cloning and sequence of a region encoding a surface polysaccharide of Vibrio cholerae O139 and characterisation of the insertion site in the chromosome of Vibrio cholerae O1. Mol Microbiol 19, 815-826.

Dicker, I. B. \& Seetharam, S. (1992). What is known about the structure and function of the Escherichia coli protein FirA? Mol Microbiol 6, 817-823.

Dietzler, D. N. \& Strominger, J. L. (1973). Characterisation of the 4-acetamido-4,6-dideoxyhexoses from Escherichia coli strains. J Biol Chem 248, 104-109.

Drummelsmith, J. \& Whitfield, C. (1999). Gene products required for surface expression of the capsular form of the group $1 \mathrm{~K}$ antigen in Escherichia coli (O9a:K30). Mol Microbiol 31, 1321-1332.

Fallarino, A., Mavrangelos, C., Stroeher, U. H. \& Manning, P. A. 
(1997). Identification of additional genes required for the Oantigen biosynthesis in Vibrio chloerae O1. J Bacteriol 179, 2147-2153.

Forest, K. T., Dunham, S. A., Koomey, M. \& Tainer, J. A. (1999). Crystallographic structure reveals phosphorylated pilin from Neisseria: phosphoserine sites modify type IV pilus surface chemistry and fibre morphology. Mol Microbiol 31, 743-752.

Fry, B. N., Korolik, V., ten Brinke, J. A., Pennings, M. T., Zalm, R., Teunis, B. J., Coloe, P. J. \& van der Zeijst, B. A. (1998). The lipopolysaccharide biosynthesis locus of Campylobacter jejuni 81116. Microbiology 144, 2049-2061.

Gruber, A. \& Zingales, B. (1995). Alternative method to remove antibacterial antibodies from antisera used for screening of expression libraries. Biotechniques 19, 28-29.

Hamadeh, R. M., Estabrook, M. M., Zhou, P., Jarvis, G. A. \& Griffiss, J. M. (1995). Anti-Gal binds to pili of Neisseria meningitidis: the immunoglobulin A isotype blocks complementmediated killing. Infect Immun 63, 4900-4906.

Haselbeck, A. \& Hösel, W. (1993). Immunological detection of glycoproteins on blots based on labelling with digoxigenin. Methods Mol Biol 14, 161-173.

Hoke, C. \& Vedros, N. A. (1982). Taxonomy of the neisseriae: deoxyribonucleic acid base composition, interspecific transformation, and deoxyribonucleic acid hybridization. Int $J$ Syst Bacteriol 32, 57-66.

Jennings, M. P., Hood, D. W., Peak, I. R., Virji, M. \& Moxon, E. R. (1995). Molecular analysis of a locus for the biosynthesis and phase-variable expression of the lacto- $\mathrm{N}$-neotetraose terminal lipopolysaccharide structure in Neisseria meningitidis. Mol Microbiol 18, 729-740.

Jennings, M. P., Virji, M., Evans, D., Foster, V., Srikhanta, Y. N., Steeghs, L., van der Ley, P. \& Moxon, E. R. (1998). Identification of a novel gene involved in pilin glycosylation in Neisseria meningitidis. Mol Microbiol 29, 975-984.

Jennings, M. P., Srikhanta, Y. N., Moxon, E. R., Kramer, M., Poolman, J. T., Kuipers, B. \& van der Ley, P. (1999). The genetic basis of the phase variation repertoire of lipopolysaccharide immunotypes in Neisseria meningitidis. Microbiology 145, 3013-3021.

Korolik, V., Fry, B. N., Alderton, M. R., van der Zeijst, B. A. \& Coloe, P. J. (1997). Expression of Campylobacter hyoilei lipooligosaccharide (LOS) antigens in Escherichia coli. Microbiology 143, 3481-3489.

van der Ley, P., Kramer, M., Martin, A., Richards, J. C. \& Poolman, J. T. (1997). Analysis of the icsBA locus required for biosynthesis of the inner core region from Neisseria meningitidis lipopolysaccharide. FEMS Microbiol Lett 146, 247-253.

Linton, K. J., Jarvis, B. W. \& Hutchinson, C. R. (1995). Cloning of the genes encoding thymidine diphospho-glucose 4,6-dehydratase and thymidine diphospho-4-keto-6-deoxyglucose 3,5-epimerase from the erythromycin-producing Saccharapolyspora erythraea. Gene 153, 33-40.

McGee, A. A. \& Stephens, D. S. (1984). Common pathways of invasion of mucosal barriers by Neisseria gonorrhoeae and Neisseria meningitidis. Surv Synth Pathol Res 174, 1-10.

Marceau, M. \& Nassif, X. (1999). Role of glycosylation at Ser63 in production of soluble pilin in pathogenic Neisseria. J Bacteriol 181, 656-661.

Marceau, M., Forest, K., Béretti, J.-C., Tainer, J. \& Nassif, X. (1998). Consequences of the loss of O-linked glycosylation of meningococcal type IV pilin on piliation and pilus-mediated adhesion. Mol Microbiol 27, 705-715.
Matsuhashi, M. \& Strominger, J. L. (1964). Thymidine diphosphate 4-acetamido-4,6-dideoxyhexoses. I. Enzymatic synthesis by strains of Escherichia coli. J Biol Chem 239, 2454-2463.

Matsuhashi, M. \& Strominger, J. L. (1966). Thymidine diphosphate 4-acetamido-4,6-dideoxyhexoses. III. Purification and properties of thymidine diphosphate 4-keto-6-deoxy-Dglucose transaminase from Escherichia coli strain B. J Biol Chem 241, 4738-4744.

Morse, S. A. \& Knapp, J. S. (1992). The genus Neisseria. In The Prokaryotes, 2nd edn, pp. 2495-2529. Edited by A. Balows, H. G. Trüper, M. Dworkin, W. Harder \& K.-H. Schleifer. New York: Springer.

Nassif, X., Lowy, J., Stenberg, P., O'Gaora, P., Ganji, A. \& So, M. (1993). Antigenic variation of pilin regulates adhesion of Neisseria meningitidis to human epithelial cells. Mol Microbiol 8, 719-725.

Parge, H. E., Forest, K. T., Hickey, M. J., Christensen, D. A., Getzoff, E. D. \& Tainer, J. R. (1995). Structure of the fibre-forming protein pilin at $2 \cdot 6 \AA$ resolution. Nature $387,32-38$.

Saiki, R. K., Gelfand, D. H., Stoffel, S., Scharf, S. J., Higuchi, R., Horn, G. T., Mullis, K. B. \& Erlich, H. A. (1988). Primer-directed enzymatic amplification of DNA with a thermostable DNA polymerase. Science 239, 487-491.

Sambrook, J., Fritsch, E. F. \& Maniatis, T. (1989). Molecular Cloning: a Laboratory Manual, 2nd edn. Cold Spring Harbor, NY : Cold Spring Harbor Laboratory.

Sau, S. \& Lee, C. Y. (1996). Cloning of type 8 capsule genes and analysis of gene clusters for the production of different capsular polysaccharides in Staphylococcus aureus. J Bacteriol 178, 2118-2126.

Sau, S., Bhasin, N., Wann, E. R., Lee, J. C., Foster, T. J. \& Lee, C. Y. (1997a). The Staphylococcus aureus allelic genetic loci for serotype 5 and 8 capsule expression contain the type-specific genes flanked by common genes. Microbiology 143, 2395-2405.

Sau, S., Sun, J. \& Lee, C. Y. (1997b). Molecular characterisation and transcriptional analysis of type 8 capsule genes in Staphylococcus aureus. J Bacteriol 179, 1614-1621.

Scholten, R. J. P. M., Kuipers, B., Valkenberg, H. A., Dankert, J., Zollinger, W. D. \& Poolman, J. T. (1994). Lipo-oligosaccharide immunotyping of Neisseria meningitidis by a whole-cell ELISA using monoclonal antibodies and association of immunotype with serogroup, serotype and subtype. J Med Microbiol 41, 236-243.

Seifert, H. S. (1996). Questions about gonococcal pilus phase- and antigenic variation. Mol Microbiol 21, 433-440.

Skurnik, M., Venho, R., Toivanen, P. \& Al-Hendy, A. (1995). A novel locus of Yersinia enterocolitica serotype O:3 involved in lipopolysaccharide outer core biosynthesis. Mol Microbiol 17, 575-594.

Smith, D. R., Doucette-Stamm, L. A., Deloughery, C. \& 34 other authors (1997). Complete genome sequence of Methanobacterium thermoautotrophicum delta $\mathrm{H}$ : functional analysis and comparative genomics. J Bacteriol 179, 7135-7155.

Sofia, H. J., Burland, V., Daniels, D. L., Lunkett, G., III \& Blattner, F. R. (1994). Analysis of the Escherichia coli genome. V. DNA sequence of the region from 76.0 to 81.5 minutes. Nucleic Acids Res 22, 2576-2586.

Stimson, E., Makepeace, K., Dell, A. \& 9 other authors (1995). Meningococcal pilin: a glycoprotein substituted with digalactosyl 2,4-diacetamido-2,4,6-trideoxyhexose. Mol Microbiol 17, 1201-1214.

Stimson, E., Virji, M., Barker, S. \& 7 other authors (1996). Discovery of a novel protein modification: alpha-glycero- 
phosphate is a substituent of meningococcal pilin. Biochem J 316, 29-33.

Stroeher, U. H., Karageorgos, L. E., Brown, M. H., Morona, R. \& Manning, P. A. (1995). A putative pathway for perosamine biosynthesis is the first function encoded within the $r f b$ region of Vibrio cholerae O1. Gene 166, 33-42.

Szymanski, C. M., Yao, R., Ewing, C. P., Trust, T. J. \& Guerry, P. (1999). Evidence for a system of general glycosylation in Campylobacter jejuni. Mol Microbiol 35, 1022-1030.

Thorson, J. S., Lo, S. F., Liu, H.-W. \& Hutchinson, C. R. (1993). Biosynthesis of 3,6-dideoxyhexoses: new mechanistic reflections upon 2,6-dideoxy, and amino sugar construction. J Am Chem Soc 115, 6993-6994.

Thorson, J. S., Lo, S. F., Ploux, O., He, X. \& Liu, H.-W. (1994). Studies of the biosynthesis of 3,6-dideoxyhexoses: molecular cloning and characterisation of the asc (ascarylose) region from Yersinia pseudotuberculosis serogroup VA. J Bacteriol 176, 5483-5493.

Tuomanen, E. I. (1996). Surprise? Bacteria glycosylate proteins too. J Clin Invest 98, 2659-2660.

Virji, M. (1997). Post-translational modifications of meningococcal pili. Identification of common substituents: glycans and $\alpha$ glycerophosphate - a review. Gene 192, 141-147.

Virji, M., Kayhty, H., Ferguson, D. J., Alexandrescu, C., Heckels, J. E. \& Moxon , E. R. (1991). The role of pili in the interactions of pathogenic Neisseria with cultured human endothelial cells. Mol Microbiol 5, 1831-1841.

Virji, M., Alexandrescu, C., Ferguson, D. J., Saunders, J. R. \& Moxon, E. R. (1992). Variations in the expression of pili: the effect on adherence of Neisseria meningitidis to human epithelial and endothelial cells. Mol Microbiol 6, 1271-1279.
Virji, M., Saunders, J. R., Sims, G., Makepeace, K., Maskell, D. \& Ferguson, D. J. (1993). Pilus-facilitated adherence of Neisseria meningitidis to human epithelial and endothelial cells: modulation of adherence phenotype occurs concurrently with changes in primary amino acid sequence and the glycosylation status of pilin. Mol Microbiol 10, 1013-1028.

Wang, L. \& Reeves, P. R. (1994). Involvement of the galactosyl-1phosphate transferase encoded by the Salmonella enterica $\mathrm{rfbP}$ gene in O-antigen subunit processing. J Bacteriol 176, 4348-4356.

Wang, L. \& Reeves, P. R. (1996). C-terminal half of Salmonella enterica $\mathrm{WbaP}(\mathrm{RfbP})$ is the galactosyl-1-phosphate transferase domain catalysing the first step of $\mathrm{O}$-antigen synthesis. J Bacteriol 178, 2598-2604.

Weiser, J. N., Goldberg, J. B., Pan, N., Wilson, L. \& Virji, M. (1998). The phosphorylcholine epitope undergoes phase variation on a 43-kilodalton protein in Pseudomonas aeruginosa and on pili of Neisseria menigitidis and Neisseria gonorrhoeae. Infect Immun 66, 4263-4267.

Wolfgang, M., Lauer, P., Park, H.-S., Brossay, L., Herbert, J. \& Koomey, M. (1998). PilT mutations lead to simultaneous defects in competence for natural transformation and twitching motility in piliated Neisseria gonorrhoeae. Mol Microbiol 29, 321-330.

Wood, A. C., Oldfield , N. J., O’Dwyer, C. A. \& Ketley, J. M. (1999). Cloning, mutation and distribution of a putative lipopolysaccharide biosynthesis locus in Campylobacter jejuni. Microbiology 145, 379-388.

Received 22 July 1999; revised 1 December 1999; accepted 16 December 1999. 